\title{
FUZZY ACTIVITY BASED LIFE CYCLE COSTING FOR REPAIRABLE EQUIPMENT
}

\author{
Freselam Mulubrhan ${ }^{\mathrm{a}}$, Ainul Akmar Mokhtar, Masdi Muhammad, \\ Mechanical Engineering Department, Universiti Teknologi PETRONAS \\ Bandar Seri Iskandar, 31750 Tronoh, Perak, Malaysia \\ frity4u@gmail.com
}

\begin{abstract}
Life-cycle cost (LCC) is the much known method used for decision making that considers all costs in the life of a system or equipment. Predicting LCCs is fraught with potential errors, owing to the uncertainty in future events, future costs, interest rates, and even hidden costs. These uncertainties have a direct impact on the decision making. Activity based LCC is used to identify the activities and cost drivers in acquisition, operation and maintenance phase. This activity based LCC is integrated with fuzzy set theory and interval mathematics to model these uncertainties. Day-Stout-Warren (DSW) algorithm and the vertex method are then used to evaluate competing alternatives. A case of two pumps (Pump A and Pump B) are taken and their LCC is analysed using the developed model. The equivalent annual cost of Pump B is greater than Pump A, which leads the decision maker to choose Pump A over Pump B.
\end{abstract}

Key words: - fuzzy set theory, activity based life cycle costing, interval mathematics

\section{Introduction}

Life cycle cost (LCC) is used as a decision support tool to aid decision makers to propose, compare, and select the cost effective alternatives for maintenance, renewal, and capital investment [1]. LCC consists of acquisition cost which incurred when the asset is purchased and ownership cost which incurred throughout the asset's life [2]. Studies show that the engineering system ownership cost can vary from 10 to 100 times higher than the original acquisition cost [3]. The cost estimation method used for determining LCC has a higher impact on producing an accurate and efficient result and needs to have the ability to grip the uncertainties raised. Predicting the future LCCs is fraught with potential errors, owing to uncertainties in; future events, failure rate, life span of equipment, future costs, interest rates, and so on [1]. Activity Based Costing (ABC) model deals with all the activities that will incur cost and it has the best capability to deal with the uncertainties [4]. It was first introduce by Kaplan and Cooper in 1988[5]. In $\mathrm{ABC}$ cost estimating techniques it is necessary to identify each activity in all the life cycle stages; acquisition, installation, operation, and disposal.

LCC can be estimated through deterministic, probabilistic or soft computing approaches. Eric and Timo [6] found that $83 \%$ of manufacturing industries used deterministic nature of LCC analysis, while only $17 \%$ employed probabilistic model. In deterministic approach, uncertainties in the input data were ignored. The probabilistic approach on the other hand accounts for the uncertainty and variation associated with input values [7]. Probabilistic method requires the defining of a probability distribution for every uncertain variable.
Defining probability for every uncertain variable requires adequate historical data. If historical data is available the method can give realistic results. However if there is no adequate historical data, which happens in most real cases, soft computing will be a more suitable method. Even if there are adequate historical data, it is necessary to polish these input data by the judgment of the experts Since these estimates are often based upon uncertain, ambiguous subjective and sometimes incomplete information, soft computing techniques emerge as a very appealing alternative for developing LCC tools [8].

Lately the application of fuzzy set theory in modeling uncertainties has an upward trend due to its appropriateness handling situations where human reasoning, human perception, or human decision making is inextricably involved [10]. Fuzzy theory is based on fuzzy sets, which is the expansion of crisp sets. Fuzzy theory overthrows the two/dual value (yes or no) so that its multi-value could be pressed close to reality. Defining fuzzy variable is a less complicated that defining random number if there is limited information.

The main objective of this research is to develop fuzzy activity based LCC is by incorporating fuzzy set theory, interval mathematics and activity based costing. This model is adapted from Mohammad Ammar, et al. 2013 [11]. In this research there are four types of uncertainties defined; cost, interest rate, life span of the equipment and number of failure. Since there is availability of historical data from existing plant number of failure is estimated using a probabilistic method. Engineering economic concept of equivalent annual cost is used to transform all the present and future costs to annual cost. Day-Stout-Warren (DSW) algorithm and 
the vertex method are then used to evaluate competing alternatives.

\section{Methodology}

In this section the develop decision support model is discussed in detail. The general framework is shown below in Figure 1.

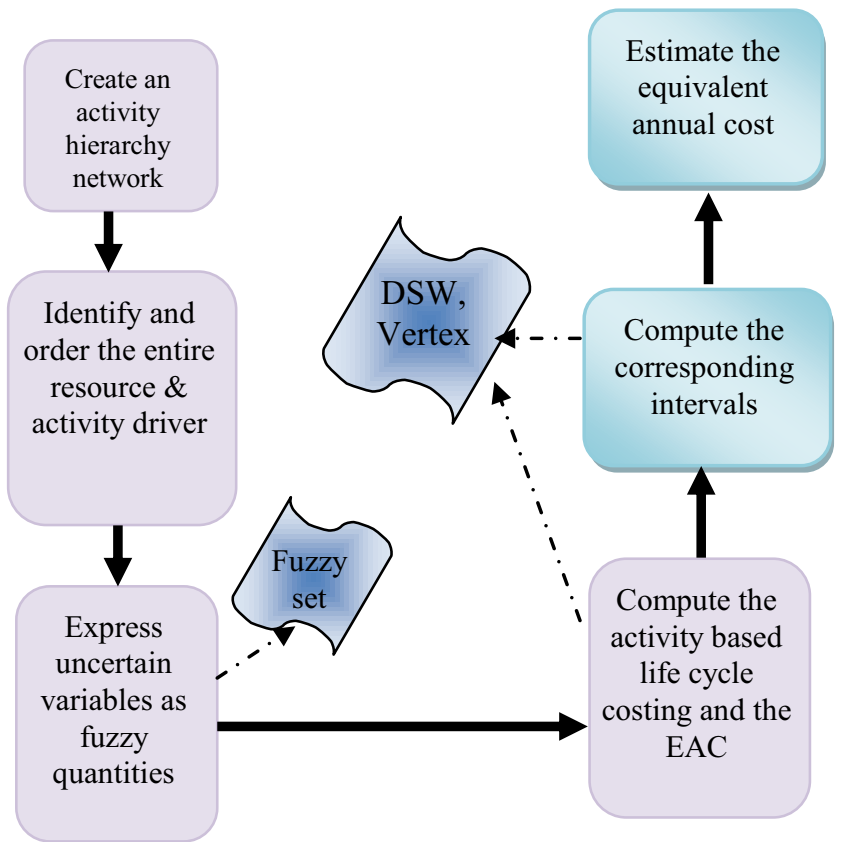

Figure 1. Schematic representation for decision support model

\subsection{Create an activity hierarchy network}

The model is applied to two different pumps manufactured by the concerned pump manufacturer (pump A and pump B). The design service life for pump $\mathrm{A}$ is 45 years and for pump B is 60 yrs. The data required for the analysis is extracted from [12] [13]. The principle of $\mathrm{ABC}$ is that products or services consume activities; activities consume resources and resources generate costs. This makes the identified activities to be cost drivers. All the activities which are the driver of the cost and their relation are identified as shown in the Table 1 below.

Table 1. Pump life cycle activities and drivers

\begin{tabular}{|l|c|}
\hline \multicolumn{1}{|c|}{ Activities } & \multicolumn{1}{c|}{ Cost driver } \\
\hline \multicolumn{2}{|c|}{ Operation } \\
\hline $\begin{array}{l}\text { Day to day } \\
\text { upervision }\end{array}$ & $\begin{array}{l}\text { Number of hours of pump } \\
\text { operation, personnel, and } \\
\text { labour }\end{array}$ \\
\hline Day to day operation & $\begin{array}{l}\text { Cost of energy and number } \\
\text { of hours of pump operation }\end{array}$ \\
\hline \multicolumn{2}{|c|}{ Corrective maintenance and repair } \\
\hline Access to the failed & $\begin{array}{l}\text { Time to gain access to failed } \\
\text { component, personnel, and } \\
\text { tools used }\end{array}$ \\
\hline Diagnosis & $\begin{array}{l}\text { Fault isolation time, } \\
\text { personnel, }\end{array}$ \\
\hline
\end{tabular}

\begin{tabular}{|l|l|}
\hline & $\begin{array}{l}\text { technical data test } \\
\text { equipments, and tools used }\end{array}$ \\
\hline Repair/replacement & $\begin{array}{l}\text { Actual hands on time to } \\
\text { repair/replacement, } \\
\text { personnel, equipments and } \\
\text { tools used }\end{array}$ \\
\hline $\begin{array}{l}\text { Verification and } \\
\text { lignment }\end{array}$ & $\begin{array}{l}\text { Time spent, personnel and } \\
\text { tools used }\end{array}$ \\
\hline
\end{tabular}

\subsection{Express the uncertainty variables as fuzzy quantities}

There are different types of fuzzy number, triangular, trapezoidal, gaussian, sigmoid and bell shape membership functions are some of it. Triangular fuzzy number is widely used in many applications.

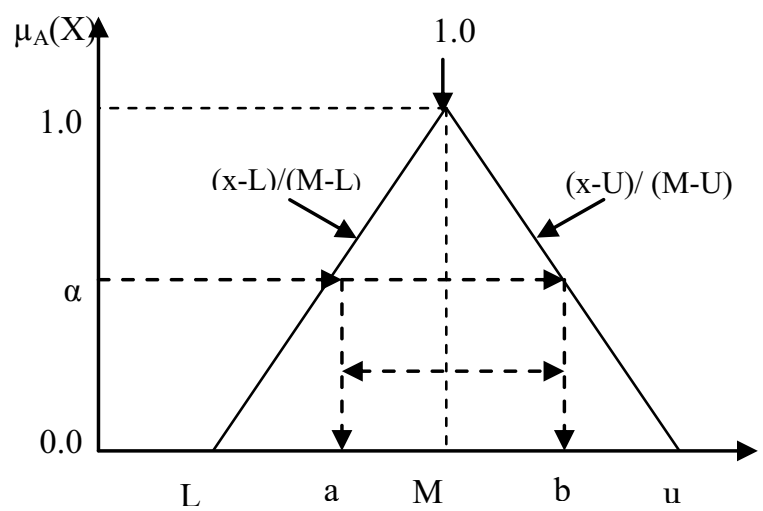

Figure 2. Triangular membership functions with $\alpha$-cut

The membership function $\left(\mu_{A}(x)\right)$ of a triangular fuzzy number which associated with a real number in the interval $[0,1]$ can be defined as:

$\mu_{A}(x)=\left\{\begin{array}{l}\frac{x}{M-L}-\frac{L}{M-L}, \ldots \ldots \ldots \ldots \ldots . . . x \in[L, M], \\ \frac{x}{M-U}-\frac{U}{M-U}, \ldots \ldots \ldots . . . x \in[M, U],\end{array}\right.$

The acquisition cost, the operation and the corrective maintenance cost is given in a fuzzy triangular number with the lower, modal and upper value as shown in Table 2. All given costs are in USD.

Table 2. Costs in triangular fuzzy number

\begin{tabular}{|l|l|l|l|l|l|l|}
\hline & \multicolumn{3}{|l|}{ Pump A } & \multicolumn{3}{l|}{ Pump B } \\
\hline & $\mathrm{L}$ & $\mathrm{M}$ & $\mathrm{U}$ & $\mathrm{L}$ & $\mathrm{M}$ & $\mathrm{U}$ \\
\hline $\begin{array}{l}\text { Acquisition } \\
\text { cost }\end{array}$ & & & & & & \\
\hline cost of pump & 2080 & 2600 & 3120 & 4844 & 5190 & 5363 \\
\hline cost of motor & 1375 & 1500 & 1688 & 21375 & 23750 & 28500 \\
\hline $\begin{array}{l}\text { cost of base } \\
\text { frame }\end{array}$ & 167 & 200 & 233 & 482 & 550 & 619 \\
\hline $\begin{array}{l}\text { Cost of } \\
\text { coupling }\end{array}$ & 25 & 30 & 35 & 213 & 250 & 313 \\
\hline Operation cost & & & & & & \\
\hline $\begin{array}{l}\mathrm{C}_{\text {pw }} \text { is cost per } \\
\text { input power }\end{array}$ & 0.08 & 0.1 & 0.12 & 0.08 & 0.1 & 0.12 \\
\hline
\end{tabular}




\begin{tabular}{|c|c|c|c|c|c|c|}
\hline$(\$ / \mathrm{kw})$ & & & & & & \\
\hline $\begin{array}{l}C_{l} \text { is cost of } \\
\text { labour per hour }\end{array}$ & 0.8 & 1 & 1.2 & 0.8 & 1 & 1.2 \\
\hline $\begin{array}{l}\text { Maintenance } \\
\text { cost }\end{array}$ & & & & & & \\
\hline $\begin{array}{l}C_{S . p} \text { is cost of } \\
\text { spare part }\end{array}$ & 160 & 200 & 240 & 160 & 200 & 240 \\
\hline $\begin{array}{l}C_{t} \text { is cost of } \\
\text { tools }\end{array}$ & & & & & & \\
\hline $\begin{array}{l}\checkmark \text { for access to } \\
\text { the failed, } \\
\text { component, } \\
\text { diagnosis, } \\
\text { verification \& } \\
\text { alignment }\end{array}$ & 2.7 & 3 & 3.4 & 2.7 & 3 & 3.4 \\
\hline $\begin{array}{l}\checkmark \text { for activity } \\
\text { repair/replacem } \\
\text { ent }\end{array}$ & 4 & 6 & 7.5 & 4 & 6 & 7.5 \\
\hline $\begin{array}{l}l \text { is cost per } \\
\text { labor }\end{array}$ & 7.5 & 8 & 9.5 & 7.5 & 8 & 9.5 \\
\hline
\end{tabular}

\subsection{Compute the activity based LCC}

In this section the fuzzy activity based LCC is developed.

$$
L C C=\widetilde{C}_{a q}+\widetilde{C}_{o p}+\widetilde{M}_{c}+\widetilde{D}_{c}
$$

where $\widetilde{C}_{a q}$ is acquisition cost, $\widetilde{C}_{o p}$ is operating cost, $\widetilde{M}_{c}$ is maintenance cost and $\widetilde{D}_{c}$ is decomposition cost. Due to unavailability of data decomposition cost is not covered.

The acquisition cost contains $\widetilde{C}_{1}$ cost of pump, $\widetilde{C}_{2}$ cost of motor, $\widetilde{C}_{3}$ cost of base frame, and $\widetilde{C}_{4}$ cost of coupling. The general expression for the acquisition cost is;

$$
\widetilde{C}_{a q}=\sum_{j=1}^{j=4} \widetilde{C}_{j}
$$

The high impact cost drivers in the operation are number of operation hours, personnel, and cost of energy. By integrating these factors the following equation is developed to estimate the operation cost. Mathematically, it is expressed as shown in Eq. (4):

$\widetilde{C}_{o p}=t *\left(\widetilde{C}_{e}(K W)+\widetilde{C}_{l}\right)$

where $t$ is the design life of pump (h), $\widetilde{C}_{e}$ is cost of energy $(\$ / \mathrm{KWH})$ and $\widetilde{C}_{l}$ is cost of labour per hour. Energy consumption is calculated by gathering data on the pattern of the system output. Cost of energy for pump can be estimated as shown below [12] [13].

$$
C_{e}=C_{p w}\left[\left(\frac{Q \cdot H}{366 \cdot \eta_{p} \cdot \eta_{m}}\right)\right]
$$

where $C_{p w}$ is cost per input power ( $\left.\$ / \mathrm{kw}\right), Q$ is the pump flow rate $\left(\mathrm{m}^{3} / \mathrm{h}\right), H$ is the pump head $(\mathrm{m}), \eta_{\mathrm{p}}$ is the pump efficiency, $\eta_{\mathrm{m}}$ is the motor efficiency. These parameters for pump A \& B are shown in Table 3.

Table 3. Parameters of Pump A and B

\begin{tabular}{|l|c|c|}
\hline Parameter & Pump A & Pump B \\
\hline pump flow rate $Q\left(\mathrm{~m}^{3} / \mathrm{h}\right)$ & 300 & 205 \\
\hline The pump head $H(\mathrm{~m})$ & 90 & 300 \\
\hline the pump efficiency $\eta_{\mathrm{p}}$ & 76 & 75 \\
\hline the motor efficiency $\eta_{\mathrm{m}}$ & 92 & 90 \\
\hline
\end{tabular}

One of the main factors which affect the reliability of an equipment of a system is proper maintenance. Uncertainties arise from maintenance cost determination, because the failure of the system can happen stochastically. The general equation of maintenance cost is as follows;

$$
\tilde{M}_{C}=\widetilde{C}_{c} N
$$

where $\tilde{M}_{C}$ is the maintenance cost, $N$ is the number of failure, and $\widetilde{C}_{c}$ is the cost of repair. The corrective maintenance is conducted whenever there is a failure and the cost of repair is estimated by the activities it perform

$$
\widetilde{C}_{c}=\widetilde{C}_{s \cdot p}+\widetilde{C}_{t}+\operatorname{MTTR}\left(l^{*} n\right)
$$

where $\widetilde{C}_{s . p}$ is cost of spare part for repairing a failure, if the pump is repaired without replacing any parts $\widetilde{C}_{s . p}$ is going to be zero. $\widetilde{C}_{t}$ is cost of tools; MTTR is mean time to repair, $l$ is cost per labor and $n$ is number of labor for each activity. Maintenance cost is therefore,

$\widetilde{M}_{c}=N\left(\widetilde{C}_{s . p}+\widetilde{C}_{t}+\operatorname{MTTR}\left(l^{*} n\right)\right)$

The number of failures can be determined from failure probability. The failure probability in this paper is determined using parametric recurrent data analysis. The number of failure for repairable system depends on the repair assumption taken. For repairable systems, generally there are two main repair assumptions, either "as good as new" or "as bad as old", but in actual practice the equipment lies somewhere in between these two conditions which is "better than old, but worse than new" [14]. Kijima and Sumita suggested a new approach called general renewal process (GRP) which is capable to cover all the three possible repair assumptions of repairable system [15]. The parametric RDA approach is based on GRP model, which provides a way to define the recurrence rate of repairable system failure overtime by considering the repair effect on succeeding failure.

There are two types of GRP models, type I and type II. In GRP type I model the system age of only the previous failure epoch i.e., the time between the previous two failures is improved. Let $V_{i}$ denote the virtual age of 
the repairable system after the $i^{\text {th }}$ corrective maintenance action, and let $V_{0}=0$. GRP type I virtual age model indicates that,

$V_{i}=V_{i-1}+q T_{i}$

where $q$ is maintenance effectiveness $0<q<1$. Under this model, each corrective maintenance action removes a portion, $1-q$, of the age accumulated during the most recent period of repairable system function. GRP type II model is extension of GRP type I model. The difference between them is on assumption about impact of repairing on the damaged incurred [16]. GRP typeII reflects the reality where the maintenance action reduces the cumulative damage of all the previous failures. It is governed by the following equation:

$V_{i}=q\left(V_{i-1}+T_{i}\right)$

Note that if $q=0$, then corrective maintenance is perfect, if $q=1$, then it is minimal and if $0<q<1$, then the corresponding repair assumption is somewhere in between perfect and minimal [17]. Under this model, the time to repairable system failure is a Weibull random variable having scale parameters $\beta>1$ and shape parameters $\lambda$.

As stated in Wahyu [15] maximum likelihood estimation (MLE) is more considered to estimate GRP model parameter $(q, \beta, \lambda)$. Greater the MLE value of the model, the best will be the statistical fit for the given data.

\subsection{Compute the corresponding intervals}

In some complex systems, it would be more reliable to give an interval estimate than a point estimate for many quantities. Interval number $I$ is defined as an ordered pair of real numbers $[a, b]$, with lower bound $a$ and upper bound $b$. When $b=a$, the interval number $[a, a]$ degenerates to a real number $a$ [18]. The $\alpha$-cut of a fuzzy set may also be represented as an interval, such that $\mathrm{A}_{\alpha}=$ [a, b], as shown in Figure 2.

The goal of interval computation is to find the minimum and the maximum of the function when the different possible values of the variables range in their intervals. The arithmetic operations on any two intervals [a, b] and [c, d] are [19],

$$
\begin{aligned}
& \lambda \cdot[a, b]=[\lambda a, \lambda b], \quad \lambda \text { is a constant } \\
& {[a, b]+[c, d]=[a+c, b+d],} \\
& {[a, b]-[c, d]=[a-c, b-d],} \\
& {[a, b] \cdot[c, d]=[a c, b d],} \\
& {[a, b] /[c, d]=[a / d, b / c],}
\end{aligned}
$$

Dong et al.1985 [11] propose the Day Stout Warren (DSW) algorithm, which is based on the $\alpha$-cut representation of a fuzzy number. The idea behind the DSW algorithm is to choose values for the $\mu_{(x)}$ and computes the corresponding intervals in $X_{1}, X_{2}, \ldots \ldots, X_{n}$.
For further details on DSW algorithm and the vertex method refer to [12] and [13]

\subsection{Fuzzy Equivalent annual cost}

Present worth method discount future amounts to the present by using the interest rate over the appropriate study period therefore before conducting an AB-LCC, the analyst must define the general parameters, such as analysis period and discount rate.

$$
\widetilde{N} \widetilde{P} \widetilde{W}_{i}=\widetilde{I} \widetilde{C}_{i}+\sum_{j=1}^{N F_{i}}\left[\widetilde{F} \widetilde{C}_{i} * 1 /(1+\widetilde{i})^{\widetilde{t}_{i j}}\right]
$$

where $\widetilde{N} \widetilde{P} \widetilde{W}$ is the net present worth, $\widetilde{I} \widetilde{C}$ is the initial cost $\widetilde{F} \widetilde{C}$ is the future cost, $\tilde{i}$ is the interest rate and $\widetilde{t}_{i j}$ the time. The equivalent annual cost (EAC) is obtained by converting the equivalent value (at a specified time, usually the present) of a given set of cash flows into a series of uniform annual payments. The Equivalent annual cost (EAC) is,

$$
\widetilde{E} \widetilde{A} \widetilde{C}_{i}=\widetilde{A} \widetilde{C}+\widetilde{N} \widetilde{P} \widetilde{W}_{i} * \widetilde{i}(1+\widetilde{i})^{\widetilde{T}_{i}} /\left[(1+\widetilde{i})^{\widetilde{T}_{i}}-1\right]
$$

where $\widetilde{A} \widetilde{C}_{i}$ is the annual cost and $\widetilde{T}$ is time

The fuzzy equivalent annual concept is adapted from Mohammad A et.al (2013) [11]. In this paper the initial cost is the accusation cost $\left(\widetilde{C}_{a q}\right)$; the future cost is the maintenance $\operatorname{cost}\left(\tilde{M}_{c}\right)$ and the operation $\operatorname{cost}\left(\widetilde{C}_{o p}\right)$ is taken as annual cost, the equivalent annual cost is therefore

$$
\widetilde{E} \widetilde{A} \widetilde{C}_{i}=\widetilde{C}_{o p}+\left\{\widetilde{C}_{a q}+\sum_{j=1}^{N F_{i}}\left[\widetilde{M}_{c} * 1 /(1+\widetilde{i})^{\tilde{t}_{i j}}\right]\right\} * \tilde{i}(1+\widetilde{i})^{\widetilde{T}_{i}} /\left[(1+\tilde{i})^{\widetilde{T}_{i}}-1\right]
$$

The DSW algorithm is used to determine the interval of the fuzzy values. Representing fuzzy values by interval is computationally more effective than other methods [9]. Using a series of $\alpha$-cuts, the corresponding intervals of problem fuzzy parameter $\left(\widetilde{r}, \widetilde{C}_{o p}, \widetilde{M}_{c}, \widetilde{C}_{a q}, t, \widetilde{D}_{c}, \widetilde{T}\right)$ can be easily determined. The vertex method is then used to determine the equivalent annual cost.

\section{RESULT AND DISCUSSION}

\subsection{Acquisition operation and Maintenance cost}

Using Eq. (3); the acquisition cost for pump $\mathrm{A}$ is found to be $(3647,4330$, and 5076) and for pump B (26914, 29740, 34795).

The energy cost per KWh and the labour cost of operation is given as a fuzzy value in Table 2 . The total cost of operation for the life cycle is then (831650.4, 
1039563, 1247476) for pump A and (1864350, 2330437, 2796525) for pump B.

Since there are no historical data the failure data is taken from another plant that uses a similar type of pump. The failure data is collected for four years and eight failures are recorded within this time for Pump A, which are given in hour; 545, 1945, 3119, 3799, 4631, 5081, 6024 and 6900. Four failures are recorded for pump B (hour); 3026, 4759, 5874, and 7015. The scale and shape parameters of Weibull and the meantime between failure and number of failure of pump are calculated. Since the solution cannot be obtain analytically, the numerical methods is applied by Weibul ++8 software. Assuming 8 working hour per day and 243 working days per year it is found that the total time used for pump A is 87480 hour and 116640 hour for pump B. It is found that the number of failure for Pump $A$ is 112 and for Pump B are 57.

Given the mean time to repair for activities; access to the failed component, diagnosis, and verification and alignment is $3 \mathrm{hr}$ and for activity repair/replacement it is $6 \mathrm{hr}$ respectively, number of personnel for all the activities is 4 . The cost of spare part, tooling cost and labour cost is given in a triangular fuzzy number as shown in Table 2.

In practice it is unlikely to change all the component of a pump for one failure which is the assumptions of perfect repair which results in a higher expected cost. Similarly the imperfect or the minimal repair will cause a minimum expected cost but will lead to an increasing number of failure. However under the combination strategy parts which face major failure will get perfect repair while other parts like pump casing, shaft, housing, motor, and coupling which face minor failure will face an imperfect repair. This strategy seems to be a more practical and financially attractive choice so the maintenance cost is estimated for this assumption using Eq. (8) is $(66830.4,78064$, and 93284.8) for pump A and $(34012,39729,47475.3)$ for pump B. Using the above given data and equations, all costs are summarized in Table 4.

Table 4. Summary of cost for all activities

\begin{tabular}{|c|c|c|c|c|c|c|}
\hline Parameter & \multicolumn{3}{|c|}{ Pump A } & \multicolumn{3}{c|}{ Pump B } \\
\cline { 2 - 7 } & L & M & U & L & M & U \\
\hline $\begin{array}{c}\text { Acquisit } \\
\text { ion cost }\end{array}$ & 3647 & 4330 & 5076 & 26914 & 29740 & 34795 \\
\hline $\begin{array}{c}\text { Operation } \\
\text { cost }\end{array}$ & 331650.4 & 1039563 & 1247476 & 864350 & 2330437 & 2796525 \\
\hline $\begin{array}{c}\text { Maintenan } \\
\text { ce cost }\end{array}$ & 363766.4 & 375000 & 390220.8 & 56830.4 & 78064 & 93284.8 \\
\hline $\begin{array}{c}\text { Interest } \\
\text { rate }\end{array}$ & 4 & 6 & 8 & 4 & 6 & 8 \\
\hline $\begin{array}{c}\text { Service } \\
\text { life }\end{array}$ & $45 \mathrm{yr}$ & $50 \mathrm{yr}$ & $55 \mathrm{yr}$ & $55 \mathrm{yr}$ & $60 \mathrm{yr}$ & $70 \mathrm{yr}$ \\
\hline
\end{tabular}

\subsection{Interval analysis and equivalent annual cost}

In this paper the alpha cuts used are $(0,0.2,0.4,0.6,0.8$, and 1$)$. The number of $\alpha$-cuts depends on the function to be calculated and the degree of accuracy needed. The interval for the 6 alpha cut value is calculated using DSW algorithm which is shown in Table 5.

Table 5. Interval Values of for all alpha cut for Pump A (PA) and Pump B (PB)

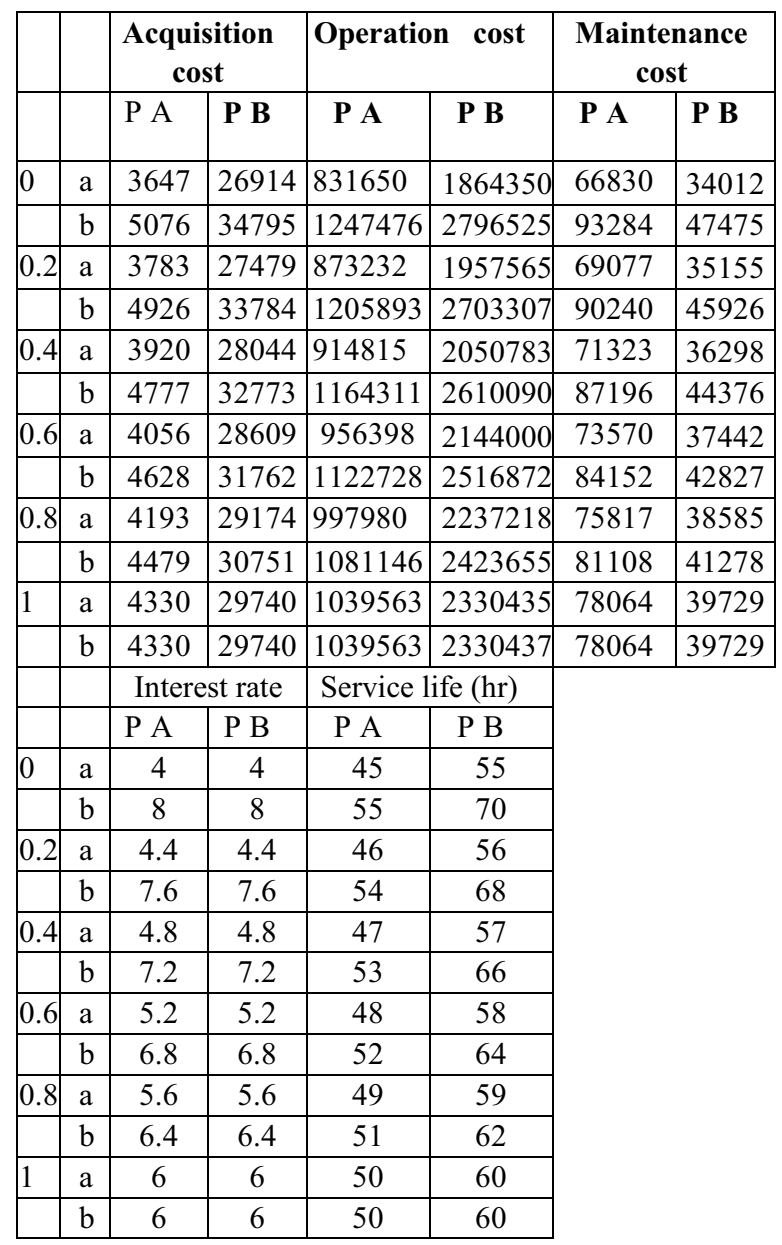

In order to explain the model $\alpha$-cut 0.6 for pump $\mathrm{A}$ is taken and the EAC for this value is calculated as shown below. The present worth factor is calculated using vertex method for interest rate of $[5.2,6.8]$ and service life $[48,52]$. The PWF is determined for the four combinations of interest rate and service life $[5.2,48]$, $[5.2,52],[6.8,48]$, and $[6.8,52]$ using Eq. (17) the PWF is found to be $[0.08775,0.07164,0.04252$, and 0.03268$]$

The minimum and maximum value is $[0.03268$, 0.08775]. The fuzzy equivalent annual cost of pump A\& $\mathrm{B}$ for the entire alpha cut is shown in Table 6 below.

Table 6. EAC result Pump A and Pump B

\begin{tabular}{|l|c|c|c|c|}
\hline \multirow{2}{*}{$\begin{array}{l}\alpha \text {-cut } \\
\text { value }\end{array}$} & \multicolumn{2}{|c|}{ Pump A } & \multicolumn{2}{c|}{ Pump B } \\
\cline { 2 - 5 } & a & b & a & b \\
\hline 0 & 832172.3 & 1248204 & 1972006 & 3074885 \\
\hline 0.2 & 874579.4 & 1206154 & 2078474 & 2960066 \\
\hline 0.4 & 915879.3 & 1164619 & 2185396 & 2846055 \\
\hline 0.6 & 957242.4 & 1123096 & 2292770 & 2732854 \\
\hline 0.8 & 998655.2 & 1081591 & 2400596 & 2620461 \\
\hline 1 & 1040107 & 1040107 & 2508875 & 2508877 \\
\hline
\end{tabular}




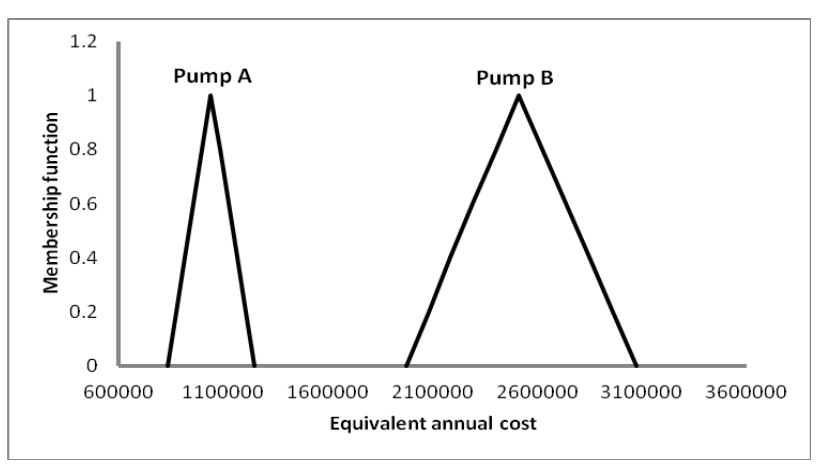

Figure 3. EAC result for all $\alpha$-cut

The value of EAC for Pump B is greater than the EAC of Pump A in all the alpha-cut values. Therefore Pump A is more preferable than Pump B.

\section{CONCLUSION}

A decision support model is developed by integrating the concept of ABC-LCC, fuzzy logic, interval analysis, DSW and vertex method. Activity based method is used to identify the activities and cost drivers in acquisition, operation and maintenance phase. Fuzzy logic is used to incorporate uncertainties in the cost value. The DSW and the vertex method are helpful in to extending ordinary algebraic operations to fuzzy algebraic. The decision made using fuzzy activity based costing is accurate since subjectivity of expert can be easily considered and thus the uncertainty can be handled. Two Pump sets, Pump A and Pump B is taken as a case for this paper. The acquisition cost of both pumps as shown in Table 4 , is very small amount of the total LCC, which shows that it is necessary to have a long-term outlook to the investment decision-making process rather than trying to save money in the short-term by simply purchasing assets with lower initial acquisition costs. From the output of the fuzzy ABC-LCC, it is found that Pump B has higher equivalent annual cost in which pump $\mathrm{A}$ is more preferable than pump B.

\section{REFERENCES}

[1] Rahman S, Vanier.D.J. Life cycle cost analysis as a decision support tool for managing municipal infrastructure. Toronto, Ontario 2004

[2] Dhillon B. S. Design reliability. Canada 1999: TA174.D4929

[3] Dhillon B. S. Life Cycle Costing for Engineers. Taylor and Francis Group, LLC 2010

[4] Emblemsvåg J, Bras B. Activity-Based Cost and Environmental Management - A Different Approach to ISO14000 Compliance. 2001 Boston: Kluwer

[5] Robin C, Robert S. Activity-Based Systems: Measuring the Costs of Resource Usage. Accounting Horizons/September 1992
[6] Korpi E, Ala-Risku T. Life cycle costing: a review of published case studies. Helsinki University of Technology Department of Industrial Engineering and Management Finland

[7] Vanier S, Rahman D.J. Life cycle cost analysis as a decision support tool for managing municipal infrastructure" National Research Council Canada-46774

[8] Chen, C., Flintsch, G.W., \& Al-Qadi, I.L. Fuzzy Logic-Based Life-Cycle Costs Analysis Model for Pavement and Asset Managemen. $6^{\text {th }}$ International Conference on Managing Pavements 2004

[9] Ross T. Fuzzy logic with engineering applications. McGraw-Hill 1995

[10] Kishk M, and Al-Hajj A. A fuzzy model and algorithm to handle subjectivity in life-cycle costing based decision-making. J. Financial Manage. Property Constr, 2002; 5(1-2), 93-104

[11] Mohammad A, Tarek Z, and Osama M. FuzzyBased Life-cycle Cost Model for Decision Making under Subjectivity. American Society of Civil Engineers 2013

[12] Waghmode L, Sahasrabudhe A, Kulkarni P. Life Cycle Cost Modelling of Pumps Using an Activity Based Costing Methodology. Journal of Mechanical Design by ASME, Vol. 132 / 1210061,2010

[13] Hennecke FW. Life cycle costs of pumps in chemical industry. ELSEVIER Chemical Engineering and Processing 38, 511-516, 1999

[14] Doyen L. Repair efficiency estimation in the ARI1 imperfect repair model. Modern Statistical And Mathematical Methods in Reliability, 2005;10:153.

[15] Wahyu W, Haryono. On Approaches For Repairable System Analysis. Laboratory of Statistical Industry, Department of Statistics FMIPA ITS Surabaya

[16] Annaruemon P, Wanida R, Supapan C, Pisal Y. A Fuzzy Time-Driven Activity-Based Costing Model in an Uncertain Manufacturing Environment. Proceedings of the Asia Pacific Industrial Engineering \& Management Systems Conference 2012

[17] Bülent B. A Critique on the Consistency Ratios of Some Selected Articles Regarding Fuzzy AHP and Sustainability. 3rd International Symposium on Sustainable Development, 2012, Sarajevo

[18] Dong W, Shah H, Wong F. Fuzzy computations in risk and decision analysis. Civ. Eng. Syst. 1985; 2(4), 201-208.

[19] Dong W, Shah H. Vertex method for computing functions of fuzzy variables. Fuzzy Sets Syst;1987: 24(1), 65-78 